\title{
The effects of crude $C$. inophyllum seed oil to silica gel mass ratio and number of stages on the isolation of wax
}

\author{
Setiyo Gunawan*, Safrina Hapsari, Hakun Wirawasista Aparamarta, Kuswandi Kuswandi, Raden \\ Darmawan
}

Department of Chemical Engineering, Faculty of Industrial Engineering, Institut Teknologi Sepuluh Nopember (ITS), Kampus ITS Sukolilo, Surabaya 60111, Indonesia

* Corresponding author: gunawan@chem-eng.its.ac.id

\section{Article history}

Received 15 April 2019

Revised 14 August 2019

Accepted 26 September 2019

Published Online 15 June 2020

\section{Graphical abstract}

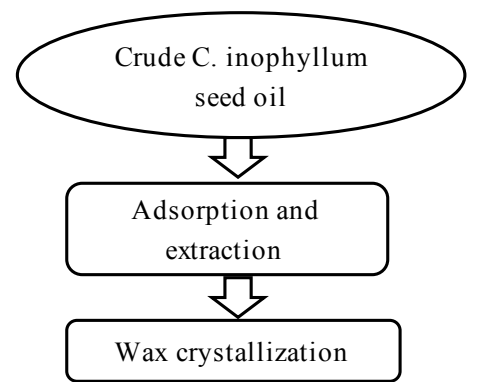

\begin{abstract}
Calophyllum inophyllum is one of the most notable mangrove species that grows a lot in the coastal areas of the Indonesian archipelago. Despite its long lifespan (50 years) and abundant seed oil production, this plant has not been utilized optimally. Wax is reported as a constituent of $C$. inophyllum seed oil, but the quantity has not been discovered yet. Wax has been commonly used as ingredient in coating, cosmetic, food, and pharmaceutical industries. The aims of this work were to separate wax from $C$. inophyllum seed oil in high purity and investigate the effects of crude $C$. inophyllum to silica gel mass ratio and the stages number on wax isolation. Silica gel was employed to adsorb crude $C$. inophyllum seed oil. Mass ratios of $C$. inophyllum seed oil to silica gel used in this work were $1: 4,1: 2$, and $1: 1(\mathrm{~g} / \mathrm{g})$. After that, the seed oil adsorbed onto silica gel was extracted by soxhlet extraction with hexane as the solvent. Wax was separated by putting the hexane extract in cold storage at $4{ }^{\circ} \mathrm{C}$ for $24 \mathrm{~h}$. Furthermore, wax obtained was analyzed by High-Temperature Gas Chromatography (HT-GC) and confirmed by Thin-Layer Chromatography (TLC). It was found that wax (purity $93.2 \%$ and yield $0.4 \%$ ) was best isolated by employing two-stage of adsorptionextraction, with crude $C$. inophyllum seed oil to silica gel mass ratio of $1: 1(\mathrm{~g} / \mathrm{g})$, followed by crystallization in cold acetone for $24 \mathrm{~h}$. Moreover, wax content in crude C. inophyllum seed oil was $0.43 \%$.
\end{abstract}

Keywords: Adsorption, Calophyllum inophyllum, extraction, silica gel, wax

\section{INTRODUCTION}

Southeast Asia is recognized as the world's largest area of mangroves, which supports 34-42 percent of the world's total. It is not only the world's largest but also the world's richest in terms of biological diversity. Five out of the top ten countries holding the world's largest mangrove forests are located in Southeast Asia. They are Indonesia (28.4\%), Malaysia (5.76 \%), Papua New Guinea (5.12 $\%)$, Myanmar (3.08 \%) and Philippines (2.53 \%) (Hamilton and Casey, 2016). A total of mangrove forests in Indonesia is about 3,112,989 ha (Giri et al., 2011). It is widely spread in Jambi, Jawa, Kalimantan Barat, Kalimantan Tengah, Lampung, Maluku Utara, Nusa Tenggara Timur, Riau, Sulawesi, Sumatera Barat, Sumatera Selatan, and Papua (Supriadi and Wicaksono, 2013).

One of the mangrove species in Indonesia, Calophyllum inophyllum, is a promising plant from the Clusiaceae family. The common names of this non-edible plant are Tamanu, Kamani (Hawaiian), Alexandrian Laurel, Borneo Mahogany (English), and Nyamplung (Indonesia). This plant is categorized as a non-edible plant because it contains poisonous resins. The tree can reach a height of 8 $25 \mathrm{~m}(26-82 \mathrm{ft})$, the leaves are dark green and deep glossy with 10-20 $\mathrm{cm}$ long (0.33-0.66 ft) and 6-8 $\mathrm{cm}(0.2-0.3 \mathrm{ft})$ wide. The light green fruits are ball-shaped, $2-5 \mathrm{~cm}$ in diameter and grow in clusters. The fruit's skin turns yellow and then brown, and gets wrinkles when it is ripened. A large brown seed (2-4 cm in diameter), surrounded in a corky shell and thin layer of pulp, is found in each fruit (Lim, 2012; Prabakaran and Britto, 2012). According to Silitonga et al. (2014), the tree yields $2000 \mathrm{~kg}$ seeds per ha.

This plant tolerates clay, calcareous, and rocky soils. However, it grows best in well-drained, sandy soils. Its lifespan is up to 50 years, tolerates high salinity or drought, and serves as a windbreaker at the seashore. The utilization of this plant does not compete with food crops (Atabani and César, 2014). All parts of it can be used to improve every aspect of a human's life. Its leaves can be the source of fiber since they contain a high amount of fiber (23,96\%) (Susanto et al., 2017). The leaves are also used to treat skin inflammation while the gum extracted from the wounded bark can be used for treating ulcers and wounds. The bark is used as antiseptic and disinfectant, the roots are applied for heatstroke. The oil from the seeds is used in the treatment of scabies and rheumatism (Dweck and Meadows, 2002). The seed oil is thick and dark green colored which has high oil content around 65-75 percent. Aparamarta (2016) reported that $C$. inophyllum seed oil can be a biodiesel feedstock because it contained triacylglycerols (TAG) $(78.30$ $\%)$, diacylglycerols (DAG) $(5.35 \%)$, monoacylglycerol (MAG) $(2.5$ $\%$ ), free fatty acids (FFA) $(8.7 \%)$, wax and other compounds (5.09\%). 
Wax is the term used to refer to any product that contains fatty materials obtained from plants, animal, marine, or mineral. It is an ester of a long chain carboxylic acid and long chain alcohol (Vali et al., 2005). Wax is considered necessary because of its characteristics. The texture of wax varies from soft to tacky to hard or breakable at $20^{\circ} \mathrm{C}$. It is insoluble in water and solubility in organic solvents is temperaturedependent. Wax melts at $40^{\circ} \mathrm{C}$ up to $140^{\circ} \mathrm{C}$ without decomposition and it can resolidify. Wax has a wide range of applications because it owns certain properties. It is applied in the coating and pharmaceutical industries as a water repellent. It is used as a dispersing medium and scratch resistance for inks, mascara, and car polish products. In lipstick and shoe polish products, it acts as an oil binder. It is used as a plasticizing medium in hot-melts and chewing gum (Tinto et al., 2017). It is applied for lubricant product because of its resistance to hydrolysis. Previously, the wax is obtained from the spermaceti organ of sperm whales. Since it is endangered whale existence and wax from refinery petrochemical is costly, other sources of wax need to be found (Ivarson et al., 2017). Wax obtained from plants is more sustainable and environmentally friendly.

In previous work, rice bran wax with the purity of $99 \%$ was isolated from crude rice bran oil by refluxing using hexane, isopropanol, and bleaching with $\mathrm{NaBH}_{4}$ (Vali et al., 2005). Gunawan et al. (2006) succeeded in obtaining rice bran wax with the purity of $99 \%$ (yield 1.4 $\%)$ from rice bran oil using modified soxhlet extraction and followed by wax crystallization in cold acetone for $24 \mathrm{~h}$. Another, Huynh et al. (2011) reported hexane extraction, acetone precipitation, isopropanol extraction, and bleaching with $\mathrm{NaBH}_{4}$ were effectively employed to isolate wax (yield $2.75 \%$ ) from dried activated sludge. These three works used materials that were already rich in wax. While Hapsari et al. (2019) reported that direct acetone crystallization and batch-wise extraction followed by acetone crystallization were unable to separate C. inophyllum wax from crude C. inophyllum seed oil (the purity of $C$. inophyllum wax obtained was low (purity $40 \%)$ ). Therefore, the purposes of this work were to obtain $C$. inophyllum wax from crude $C$. inophyllum seed oil in high purity and to determine its content. The effects of crude $C$. inophyllum seed oil to silica gel mass ratio and the number of stages on wax isolation were systematically investigated.

\section{EXPERIMENTAL}

\section{Materials}

Crude C. inophyllum seed oil was obtained from Koperasi Jarak Lestari (Cilacap, Central Java, Indonesia). Thin-layer chromatography (TLC) aluminum plates $(20 \mathrm{~cm} \times 20 \mathrm{~cm} \times 250 \mu \mathrm{m})$ from Merck (Darmstadt, Germany). Silica gel (70-230 mesh) was obtained from Merck (New York, USA). Characteristics of the gel according to the manufacturer were as follows: $0.063-0.200 \mathrm{~mm}$ particle size; 60 A pore size; $\mathrm{pH} 7$; and $480-540 \mathrm{~m}^{2} / \mathrm{g}$ specific surface area. Standard nonacosane, farnesene, cholesta-3,5-diene, squalene, fatty acids, $\alpha$-, $\delta$ , $\gamma$ - tocopherol, monooleylglycerol, diolein, triolein, and tripalmitin were obtained from Sigma Chemicals Company (St. Louis, MO). Standard rice bran wax was a gift from Taiwan Tech. The dimension of extraction chamber was extraction top joint ( $45 / 50 \mathrm{~mm}$; $30 \mathrm{~mm}$ i.d.); capacity $(85 \mathrm{~mL})$; extractor lower joint $(24 / 40 \mathrm{~mm})$; and glass thimble size $(35 \times 90 \mathrm{~mm})$. Filter paper, acetone, hexane, ethyl acetate, and acetic acid were obtained from commercial sources. All reagents were either high-performance liquid chromatography grade or analytical grade.

\section{Separation of nonpolar lipids from crude $C$. inophyllum seed oil by adsorption and extraction}

Separation of nonpolar lipids from crude C. inophyllum was conducted in two methods as two independent variables. The methods were one-stage and two-stage of adsorption and extraction. For the first stage of adsorption and extraction, crude C. inophyllum seed oil ( $8 \mathrm{~g})$ was dissolved in $100 \mathrm{~mL}$ hexane in a mixing vessel and then it was heated to $50{ }^{\circ} \mathrm{C}$. Next, the silica gel was added according to the mass ratio variables. Mass ratios of C.inophyllum seed oil to silica gel were $1: 4,1: 2$, and $1: 1(\mathrm{~g} / \mathrm{g})$. Mass ratios of solid to solvent were 10:25, 6:25, and 4:25 (g/mL). The mixture was stirred at $300 \mathrm{rpm}$ for $1 \mathrm{~h}$ with a magnetic stirrer as described by previous work (Gunawan et al., 2006). After that, silica gel was separated from hexane using filter paper and laboratory funnel. The filtrate colour was clear and discarded. The sample-loaded silica gel was then wrapped with filter paper and it was introduced into soxhlet extractor $(140 \mathrm{~mL})$ where the desorption took place. The nonpolar lipids were extracted by hexane $(140 \mathrm{~mL})$ at $68^{\circ} \mathrm{C}$ for $6 \mathrm{~h}$ (24 cycles). After completion of desorption, hexane was evaporated by distillation to obtain hexane extract or nonpolar lipid fraction in the first stage (NPLF-1). The remaining lipid in silica gel was extracted by ethyl acetate at $78{ }^{\circ} \mathrm{C}$ and the extract was designated as polar lipid fraction stage 1 (PLF-1).

For the second stage, NPLF-1 was mixed with hexane in a mixing vessel and it was heated to $50{ }^{\circ} \mathrm{C}$. Then, silica gel was added to the mixture. The mass ratio of NPLF-1 to silica gel in the second stage was equal to the mass ratio used in the stage before. The mixture was stirred with a magnetic stirrer. After that, the sample-loaded silica gel was separated and it was wrapped with filter paper. Then, the sample-loaded silica gel was extracted with hexane in soxhlet extractor and then extracted with ethyl acetate. The hexane extract was collected and concentrated by distillation at $68^{\circ} \mathrm{C}$ to remove hexane. The extract was designated as nonpolar lipid fraction in stage 2 (NPLF-2) as can be seen in Fig. 1. While the ethyl acetate extract was designated as polar lipid fraction 2 (PLF-2). There was no second stage employed after for onestage adsorption and extraction variable.

\section{Separation of wax from nonpolar lipids by acetone crystallization}

NPLF obtained from the step before was dissolved in acetone and the ratio of NPLF to acetone used was $1: 40 \mathrm{~g} / \mathrm{mL}$. The mixture was heated at $40{ }^{\circ} \mathrm{C}$ for 30 minutes and it was stirred with a magnetic stirrer. After that, it was cooled to room temperature before keeping it at $4{ }^{\circ} \mathrm{C}$ for $24 \mathrm{~h}$. After $24 \mathrm{~h}$, the solid phase formed was separated from the liquid phase using filter paper and laboratory funnel. The solid phase was washed with acetone $(3 \times 10 \mathrm{~mL})$ to eliminate the impurities and filtered then. Next, the solid phase on filter paper was dried at room temperature and followed by TLC analysis. The wax purity in the solid phase was analyzed by HT-GC as can be seen in Fig. 1. The yield was calculated as:

Wax yield $(\%)=($ wax purity $\times$ solid phase, $\mathrm{g}) /$ crude $C$. inophyllum seed oil, $g$

\section{High-temperature gas chromatography analysis}

Quantitative and qualitative analyses of samples were performed on a Shimadzu GC-2010 (Kyoto, Japan) gas chromatograph equipped with a Flame Ionization Detector (FID). Separations were carried out on a DB- 5HT (5\%-phenyl)-methylpolysiloxane nonpolar column $(15 \mathrm{~m} \times$ $0.32 \mathrm{~mm}$ i.d.; Agilent Technologies, Palo Alto, CA). The temperatures of injector and detector were both set at $370{ }^{\circ} \mathrm{C}$. The initial temperature of the column was $80^{\circ} \mathrm{C}$, and then increased to $305^{\circ} \mathrm{C}$ at $15^{\circ} \mathrm{C} / \mathrm{min}$, then to $335^{\circ} \mathrm{C}$ at $5{ }^{\circ} \mathrm{C} / \mathrm{min}$ and maintained at $335^{\circ} \mathrm{C}$ for $5 \mathrm{~min}$. Finally, the temperature was raised to $365^{\circ} \mathrm{C}$ at $15^{\circ} \mathrm{C} / \mathrm{min}$. The split ratio was 1:50. The ignition gas was hydrogen while the carrier gas was nitrogen. Ten milligrams of sample was dissolved in $1 \mathrm{~mL}$ of ethyl acetate, and $1 \mu \mathrm{L}$ of the sample was injected into the instrument.

\section{Thin-layer chromatography analysis}

Thin-layer chromatography was used to analyze samples qualitatively. The aluminum plate coated with a thin layer of silica gel was stained with samples using TLC spotting capillary tubes. After that, the plate was developed in a mixture of solvent (hexane: ethyl acetate: acetic acid $=90: 10: 1, \mathrm{~mL} / \mathrm{mL}$ ), in a covered beaker glass. The different compounds carried by the solvent would travel up the plate and reached a different height by the mobile phase. The compounds were eluted and separated into different spots on the plate. Then, the spots were visualized by putting the plate under ultraviolet light with a $254 \mathrm{~nm}$ wavelength. 


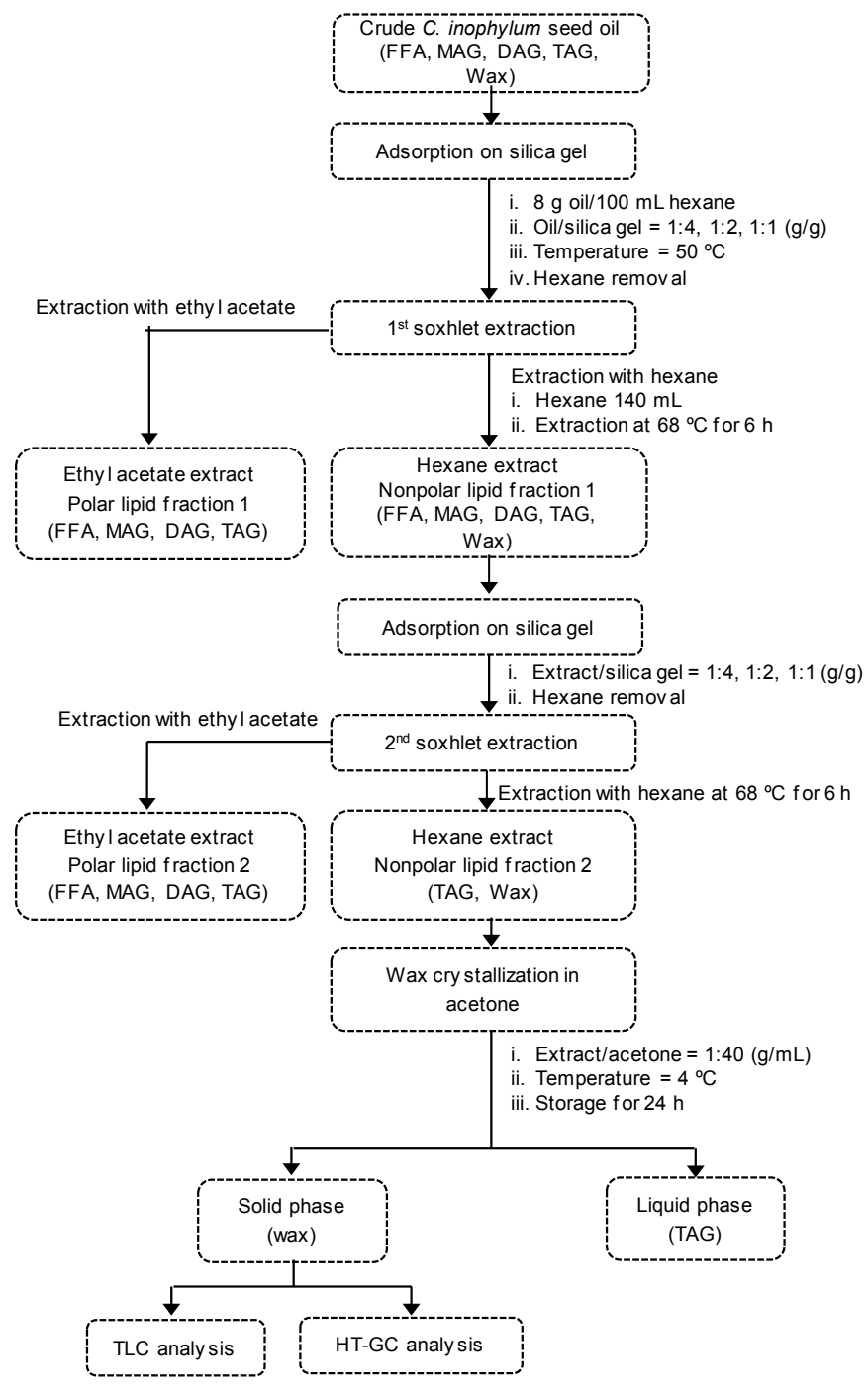

Fig. 1 Flowchart showing two-stage of wax isolation from crude $C$. inophyllum seed oil.

\section{RESULTS AND DISCUSSION}

\section{Separation of nonpolar lipids from crude C. inophyllum seed oil by adsorption and extraction}

This method used the principle of adsorption-desorption by using silica gel as an adsorbent. A mixture of crude $C$. inophyllum seed oil and hexane produced a dark green solution. An amount of silica gel was added at $50{ }^{\circ} \mathrm{C}$ due to wax's melting point. The mixture was stirred with a magnetic stirrer for $1 \mathrm{~h}$ to maximize the adsorption process as described by previous work (Gunawan et al., 2006). After completion, the mixture of hexane and crude $C$. inophyllum seed oil, which formerly in dark green, was turned to clear due to the crude $C$. inophyllum seed oil's compounds that had been adsorbed by silica gel as confirmed by TLC analysis. Basically, silica gel is a polar compound and strong adsorbent. However, nonpolar compounds can also be adsorbed by silica gel even though the bond is weak (Fabian et al., 2009). In soxhlet extractor, the desorption took place. The nonpolar compound that adsorbed onto silica gel surface was dissolved and carried by hexane through soxhlet extraction. In the second stage, the compounds contained in the NPLF-1 were adsorbed by silica gel with the same mass ratio at the first stage. Crude $C$. inophyllum seed oil was rich in TAGs and it also contained with MAGs, DAGs, FFA, wax and other compounds. The purpose of this stage was to reduce unwanted compounds such as TAGs, DAGs, MAGs, and FFAs. After that, silica gel was extracted with the second soxhlet extraction. After the extraction was completed, hexane was evaporated and the hexane extract obtained was designated as NPLF-2.

\section{Separation of wax from nonpolar lipids by acetone crystallization}

Wax in vegetable oils could be isolated by crystallizing in a ketonic solvent, such as acetone and methyl ethyl ketone. It was followed by filtering and weighing the solid phase formed (Gunawan et al., 2006). Crystallization of NPLF in acetone, followed by washing it with acetone, yielded a white solid phase. This solid phase was further analyzed by HT-GC and TLC to know its wax content. In this study, the term of wax purity indicated on how pure wax in the solid phase obtained from acetone crystallization and to know the absence of impurities in the solid phase. Figure 2 shows that the smaller the mass ratio of crude $C$. inophyllum seed oil to silica gel, the smaller the wax purity obtained. The lowest wax purity $(8.22 \pm 2.82 \%)$ was obtained by employing one-stage of adsorption and extraction, and using crude C. inophyllum seed oil to silica gel mass ratio of $1: 4(\mathrm{~g} / \mathrm{g})$. The highest wax purity $(93.20 \pm 1.23 \%)$ was obtained by employing two-stage of adsorption and extraction, and using crude $C$. inophyllum seed oil to silica gel mass ratio of 1:1 (g/g). Bigger mass ratio indicated that lesser silica gel was used. Therefore, fewer compounds were adsorbed onto the porous of silica gel, since silica gel is a porous adsorbent (Suzuki, 1991). Less silica gel made the attached compounds to be easier to dissolve in hexane when the desorption occurred. While more silica gel made the desorption more difficult because more compounds filled the porous of silica gel or attached to its surface.

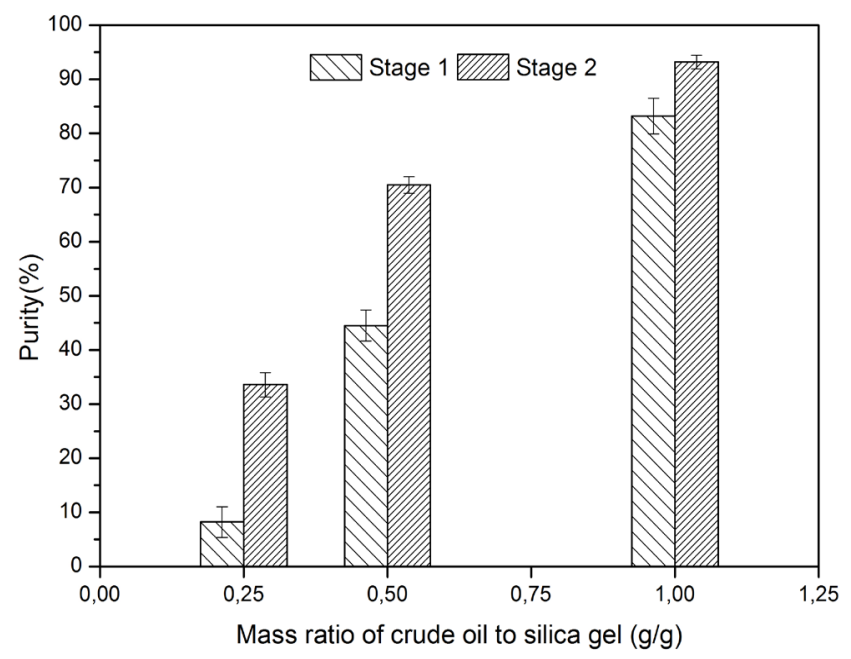

Fig. 2 The effect of crude $C$. inophyllum seed oil to silica gel mass ratio and number of stages on the wax purity

Two-stage of adsorption and extraction could produce a higher level of wax purity compared to the application of only one-stage adsorption and extraction. Moreover, a direct crystallization from crude C. inophyllum seed oil was failed to obtain wax (Hapsari et al., 2019). It happened because two-stage of adsorption and extraction could significantly reduce the number of saturated compounds. These saturated compounds were easy to crystallize along with wax in cold acetone (Kellens and Hendrix, 2000). According to Aparamarta (2017), crude $C$. inophyllum seed oil was indeed contained with saturated triacylglycerides which have saturated fatty acids, such as $\mathrm{C}_{16}, \mathrm{C}_{17}, \mathrm{C}_{18}$, $\mathrm{C}_{20}$, and $\mathrm{C}_{22}$. The term wax yield showed on how much wax obtained per crude $C$. inophyllum seed oil used. The bigger the crude $C$. inophyllum seed oil to silica gel mass ratio and the number of stages, the more wax was obtained as shown in Fig. 3. The lowest wax yield $(0.03 \pm 0.01 \%)$ was obtained by employing one-stage of adsorptionextraction and using crude $C$. inophyllum seed oil to silica gel mass ratio of $1: 4(\mathrm{~g} / \mathrm{mL})$. The highest wax yield $(0.4 \pm 0.04 \%)$ was achieved by employing two-stage of adsorption-extraction and using crude $C$. inophyllum seed oil to silica gel mass ratio of $1: 1(\mathrm{~g} / \mathrm{mL})$. This result is was proportional to the value of purity. More stages would eliminate more impurities from the solid phase. However, crude $C$. inophyllum seed oil to silica gel ratios that more than $1(\mathrm{~g} / \mathrm{g})$ and the number of stages that more than 2 didn't give successful and better separation. To 
confirm that wax did not exist in PLF, storage of PLF in acetone at 4 ${ }^{\circ} \mathrm{C}$ for $24 \mathrm{~h}$ showed no solid phase formed.

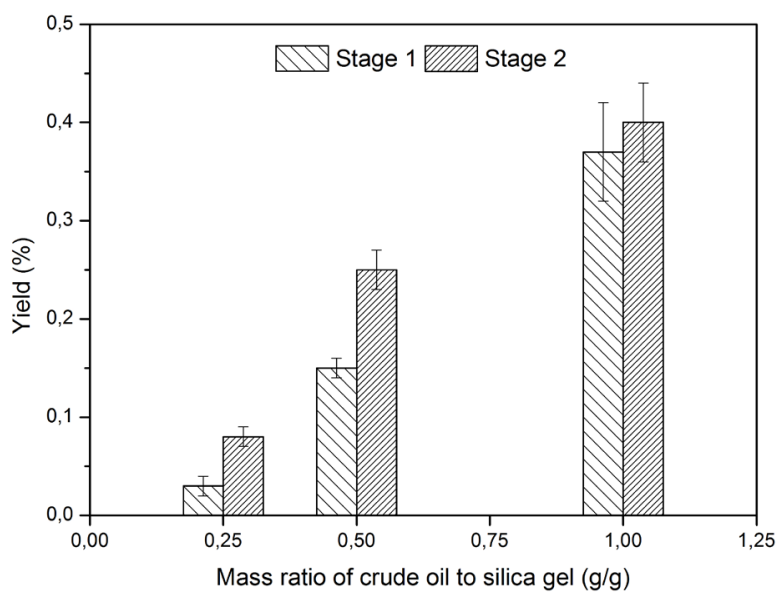

Fig. 3 The effect of crude $C$. inophyllum oil to silica gel mass ratio and number of stages on the wax yield.

Silica gel has a hydroxyl group which causes it to be a polar compound. While TAGs (glycerin with three fatty acids attached) do not have an $\mathrm{OH}$ group and the long chains are composed of $\mathrm{C}$ and $\mathrm{H}$ atoms, which have low polarity. They are different from FFAs, DAGs, and MAGs which each of them has $\mathrm{OH}$ groups at the end of the chain. Those three compounds have one or two $\mathrm{OH}$ groups attached in the glycerin structure, making them more polar than TAGs. As with the principle of "like dissolve like", polar compounds prefer to attach to polar compounds while nonpolar compounds prefer to attach to nonpolar compounds. Therefore, when desorption was occured, TAGs and wax would be easily released from the surfaces or pores of the silica gel, before dissolving in hexane, which also has low polarity. Whereas FFAs, DAGs, and MAGs were more attached to the surfaces or pores of silica gel. The results of the separation analysis by gas chromatography and TLC can be seen in Fig. 4 and Fig. 5.

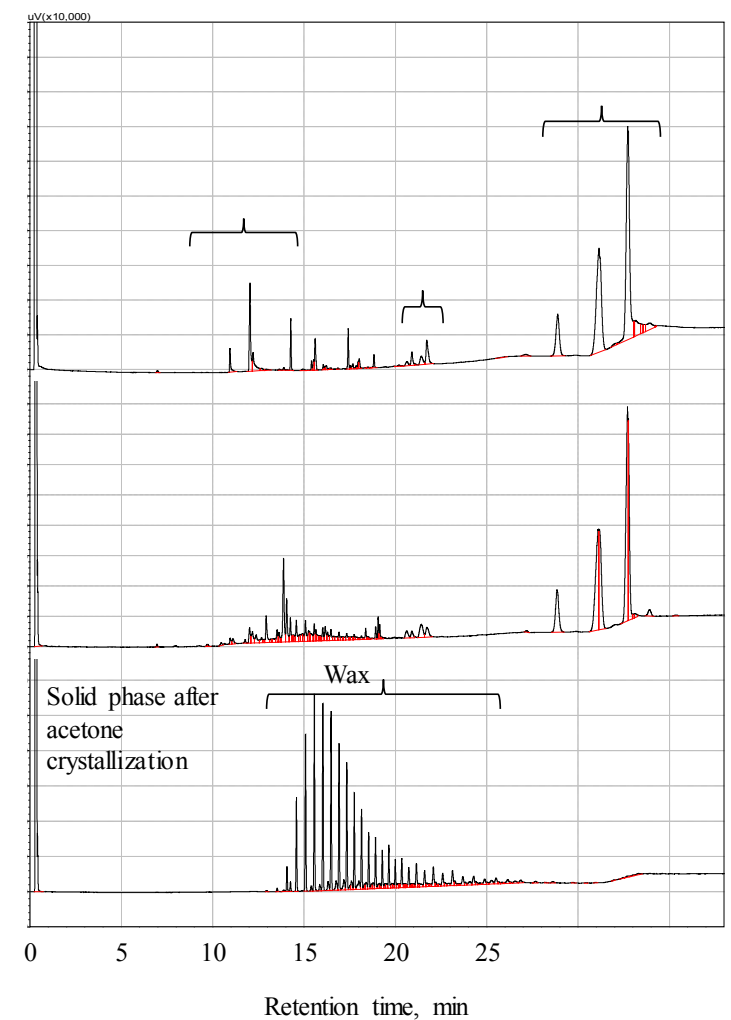

Fig. 4 GC chromatogram comparison of $C$. inophyllum seed crude oil, NPLF at the second stage, and solid phase. Operation condition for twostage of isolation and crude $C$. inophyllum seed oil to silica gel mass ratio $=1: 1(\mathrm{~g} / \mathrm{g})$.

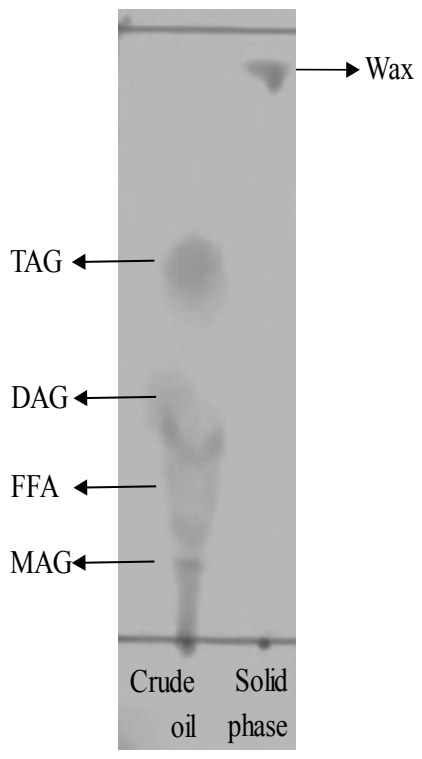

Fig. 5 The TLC analysis of crude oil and solid phase from acetone crystallization. Operation condition for two-stage of isolation and crude C. inophyllum seed oil to silica gel mass ratio $=1: 1(\mathrm{~g} / \mathrm{g})$.

Fig. 4 shows the comparison between crude C. inophyllum seed oil, NPLF in the second stage, and solid phase obtained from acetone crystallization. Initial crude $C$. inophyllum seed oil consisted of many compounds and three visible TAGs peak showed that they were the main compounds. It was difficult to quantify wax in crude oil because the wax peak was not recognized and it was detected as a tiny peak. Therefore, calculating wax recovery was difficult. After the second stage of adsorption and extraction, TAGs still dominated other compounds in the crude oil. However, after NPLF-2 was crystallized in cold acetone for $24 \mathrm{~h}$, the peaks of TAGs is were nowhere to be seen and wax peak became more visible. The result indicated that there was no TAGs detected in the white solid phase and TAGs had been successfully separated from the solid phase. The GC analysis result was supported by TLC analysis result. In TLC analysis, compounds that adsorbed the ultraviolet light would appear as the dark spots and the location of the spots showed their relative polarity. The less polar compound traveled further and more polar compound traveled less far. This condition occured because the TLC plate was layered by thin silica gel and mobile phase used was less polar. As a result, the more polar compound did not travel further because it attached to the silica gel layer. Meanwhile, less polar compound traveled further because it was transported by the mobile phase. Fig. 5 confirms that the solid phase obtained has only one spot, which was known as the wax spot, indicating that by employing two-stage adsorption-extraction and using C. inophyllum seed oil to silica gel mass ratio $1: 1(\mathrm{~g} / \mathrm{g})$, solid phase with high wax content could be produced. In contrast, crude oil has many spots because the compounds inside were varied. Wax spot was absence in crude oil because wax content was too low, therefore it was not detected. The spots location was also in accordance with the characteristic of wax. Wax was less polar than TAG because wax spot's location was further than TAG spot from the starting line.

To confirm other wax characteristics, wax obtained in this work was dissolved in an organic solvent. The organic solvent used was ethyl acetate. Evidently, it was insoluble in ethyl acetate at room temperature. In contrast, it was soluble in ethyl acetate when it was heated at $50{ }^{\circ} \mathrm{C}$. This result was consistent with wax solubility reported by Gunawan et al. (2008). Therefore, wax was successfully isolated in this work. The yield value of this work was better than the one reported by Hapsari (2019) and less than the previous study using rice bran oil $(1.33 \pm$ $0.22 \%$ ) (Gunawan et al., 2006). It was because the raw material used in this study was consisted of high levels of saturated compounds which made the separation more difficult and challenging, and also wax was minority compound in crude $C$. inophyllum seed oil. 


\section{CONCLUSION}

Calophyllum inophyllum seed oil has the potential to be the source of natural wax. The smallest mass ratio of crude $C$. inophyllum seed oil to silica gel yielded smallest wax purity and wax yield obtained. Employing two-stage of adsorption and extraction yielded wax purity and wax yield better than employing one-stage of adsorption and extraction. Wax could be isolated by separating nonpolar lipid with silica gel adsorption and extraction, and then followed by wax crystallization in cold acetone. It was found that wax (purity $93.2 \%$ and yield $0.4 \%$ ) was best isolated by employing two-stage of adsorptionextraction, with crude $C$. inophyllum seed oil to silica gel mass ratio of $1: 1(\mathrm{~g} / \mathrm{g})$, followed by crystallization in cold acetone $\left(4^{\circ} \mathrm{C}\right)$ for $24 \mathrm{~h}$.

\section{ACKNOWLEDGMENT}

The authors would like to thank Directorate General of Resources for Science, Technology and Higher Education, Ministry of Research, Technology and Higher Education of Republic Indonesia for the financial support (716/PKS/ITS/2019) in this research.

\section{REFERENCES}

Aparamarta, H. W., Saputra, T., Claratika, A., Ju, Y. H., Gunawan, S. 2016 Separation and Purification of Triacylglycerols from Nyamplung (Calophyllum inophyllum) Oil by Batchwise Solvent Extraction. Ind. Eng. Chem. Res. 55, 3113-3119.

Aparamarta, H. W., Anggraini, D., Istianingsih, D., Susanto, D.F., Widjaja, A., Ju, Y.H., Gunawan, S. 2017. Fatty Acid Fragmentation of Triacylglycerol Isolated From Crude Nyamplung Oil. AIP Conference proceeding 1840 060004-1-060004-8.

Atabani, A. E., César, S. 2014. Calophyllum inophyllum L. - A prospective nonedible biodiesel feedstock. Study of biodiesel production, properties, fatty acid composition, blending and engine performance, Renew. Sust. Energ. Rev. 37, 644-655.

Fabian, C., Gunawan, S., Kasim, N. S., Chiang, C. L., Ju, Y. H. 2009. Separation of Nonpolar Lipid from Soybean Oil Deodorizer Distillate by Stirred BatchWise Silica Gel Adsorption-Desorption. Sep. Sci. Technol. 44, 1621-1637.
Giri, C, Ochieng, L., Tieszen, L. L., Zhu, Z., Singh, A., Loveland, T., Masek, J., Duke, N. 2011. Status and distribution of mangrove forests of the world using earth observation satellite data, Global Ecol. Biogeogr. 20, 154-159.

Gunawan, S., Vali, S. R., Ju, Y. H. 2006. Purification and identification of rice bran oil fatty acid steryl and wax esters. J. Am. Oil Chem' Soc. 83, 1-8.

Gunawan, S., Fabian, C., Ju, Y. H. 2008. Isolation and Purification of Fatty Acid Steryl Esters from Soybean Oil Deodorizer Distillate. Ind. Eng. Chem. Res. 47, 7013-7018.

Hamilton, S. E., Casey, D. 2016. Creation of high spatio-temporal resolution global database of continuous mangrove forest cover for the $21^{\text {st }}$ century (CGMFC-21). Global Ecol. Biogeogr. 25, 729-738.

Hapsari, S., Susanto, D. F., Aparamarta, H. W., Widjaja, A., Gunawan, S. 2019. Separation and purification of wax from nyamplung (Calophyllum inophyllum) seed oil. Mater. Sci. Forum 964, 1-6.

Huynh, L., Do, Q. D., Kasim, N. S., Ju, Y. H. 2011. Analysis of wax esters from activated sludge. Bioresour. Technol. 102, 9518-9523.

Ivarson, E., Iven, T., Sturtevant, D., Ahlman, A., Cai, Y., Chapman, K. 2017. Production of wax esters in the wild oil species Lepidium campestre. Ind. Crops Prod. 108, 535-542.

Kellens, M., Hendrix, M. 2000. Fractionation, in O’Brien, R. D., Farr, W. E., Wan, P. J. (Eds) Introduction to Fats and Oils Technology, AOCS Press, Illinois. 194-207.

Lim, T. K. 2012. Fruits, in Edible Medicinal and Non-medicinal Plants: Volume 2, New York: Springer Science+Bussiness Media B. V. 7-20.

Prabakaran, K, Britto, S. J. 2012. Biology agroforestry and medicinal value of Calophyllum inophyllum L. (Clusiaceae): a review. Int. J. Nat. Prod. Res. 1(2), 24-33.

Silitonga, A. S., Ong, H. C., Mahlia, T. M. I., Masjuki, H. H., Chong, W. T. 2014. Biodiesel conversion from high FFA crude Jatropha curcas, Calophyllum inophyllum and Ceiba pentandra oil. Energy procedia. 61, 480-483.

Supriadi, H and Wicaksono, I. N. A. 2013. Keragaman tanaman nyamplung di taman wisata alam Pangandaran, Jawa Barat. Warta Penelitian dan Pengembangan Tanaman Industri. 19 (1).

Susanto, D. F., Aparamarta, H. W., Widjaja, A., Gunawan, S. 2017. Identification of phytochemical compounds in Calophyllum inophyllum leaves. Asian Pac. J. Trop. Biomed. 7, 773-781.

Suzuki, M. 1991. Adsorption Engineering, Kodansha, Ltd., Tokyo. 5-33.

Tinto, W. F., Elufioye, T. O., Roach, J. 2017. Waxes, in Badal, S., Delgoda, R (Eds) Pharmacognosy, Elsevier Inc., London, 443-455.

Vali, S. R., Kaimal, T. N. B., Chern, Y. T., Ju, Y. H. 2005. A process for the preparation of food-grade rice bran wax and the determination of its composition. J. Am. Oil Chem. 'Soc. 82, 57-64. 